\title{
Crossover of Discrete Emotion and its Effect on Employees' Wellbeing
}

\author{
Dayang Siti Aisah Binti Abang Suhaili ${ }^{1}$ \\ Zaiton Hassan ${ }^{2 *}$ \\ Shahren Ahmad Zaidi Adruce ${ }^{3}$
}

$\overline{1,2,3}$ Universiti Malaysia Sarawak, 94300 Kota Samarahan, Sarawak, Malaysia

\begin{abstract}
The purpose of this study is threefold, that is, to examine discrete emotion and how it could contribute to the crossover phenomena in organizations, to examine how crossover affect employees' burnout and engagement, to develop a theoretical framework of discrete emotion as mediator and its crossover in the relationship between job demand, resource and employees' wellbeing. This paper examined past studies from Proquest, SAGE, Springer, JStor and Emerald online Database that are related to discrete emotion, spillover-crossover model, burnout and engagement. Fifty papers were reviewed from the online databases within the year 2004 to 2015. Findings show that discrete emotion has some effect on employees' wellbeing through crossover phenomena process. Positive emotions, such as, joy and happiness can accelerate a person's recovery from the physiological effects of negative emotions. Employees react to the antecedent and possess a discrete emotion. Employees' discrete emotion makes crossover towards colleagues and triggers the intensity of their psychological state (engage, burnout). Practical intervention for human resource development professionals were suggested to assist employees and organizations on making it known about knowledge on discrete emotion and how it can affect employees' wellbeing. This research produces a theoretical concept to examine the predictive potential of discrete emotion that leads to crossover phenomena in determining employees' burnout and engagement.
\end{abstract}

Keywords: discrete emotion; spillover-crossover; burnout; engagement

\section{INTRODUCTION}

\section{ARTICLE INFO}

E-mail address:

hzaiton@unimas.my (Zaiton Hassan)

*Corresponding author

ISSN: 2462-1153

(C) Faculty of Cognitive Sciences and Human Development, Universiti Malaysia Sarawak (UNIMAS)
The effectiveness of teamwork in the organization is the very important element of modern management practices and it has become a research interest by previous researchers (Chin, 2015; Costa, Passos, \& Barata, 2015; Ezziane, Maruthappu, Gawn, Thompson, Athanasiou, \& Warren, 2012; Salas, Cooke, \& Rosen, 2015). However, maintaining the harmonious working relationship of teamwork's so- 
cial interaction is not easy, especially if job demand is very high. According to Bakker, Demerouti and Verbeke (2004), job demand refer to physical, psychological, social, or organizational aspects of the job that require sustained physical and/or psychological (cognitive and emotional) effort. So, emotion is part of demands of teamwork in the organization.

Emotion plays an important role in employees' daily life. It is because emotion is related to the important factor in mental health and wellbeing (Gross \& John, 2003; Schutte, Manes, \& Malouff, 2009). The nature of job or work environment may create conflict among employees in the organization that can lead to emotional reaction and affect employees' wellbeing through crossover phenomena. Crossover is not a new topic, however, the understanding of the crossover process is still in its infancy (Härtel \& Page, 2009). Due to this situation, it is not clearly known if employees face positive or negative crossover phenomena in accomplishing their work.

Crossover is defined by Westman, Vinokur, Hamilton, and Roziner (2004a) as a psychological strain experienced by a person that affects the level of strain of another person in the same social environment. As a result of this, employees could be affected with the psychological strain experienced by their friend or colleague at their workplace (Shimazu \& Schaufeli, 2009). Though spillover-crossover model will be examined but this paper only focuses on the process of crossover among colleagues at the workplace with the intention to develop the theoretical framework of crossover discrete emotions to be examined in future research. Discrete emotion is very important because it enables prediction of organizational outcomes (Lee \& Allen, 2002; Vecchio, 2000). Discrete emotional crossover becomes a moderator to predict employees' wellbeing in the organizations.

\section{Statement of problem}

The research on crossover implicates that there are positive as well as negative crossover. Even though there are research works conducted on this issue, there are still many gaps that need to be explored relating to this crossover phenomena. Bakker (2005) and Westman (2001) mentioned that there are gaps and shortage of research efforts that examine positive crossover and suggesting that more research should be done on crossover of positive phenomena. Thus, this present study will attempt to identify positive and negative crossovers among employees.

Other than that, the nature of crossover phenomena will affect peoples' wellbeing such as level of strain of others. Thus, burnout or engagement experience by employees may crossover to other people. However, these phenomena tend to focus more on emotional or psychological states, such as, depression (e.g., Joiner \& Katz, 1999), burnout (Bakker, Emmerik, \& Euwema, 2006; Westman, \& Etzion, 2001), stress (Westman , 2001), job exhaustion (Demerouti, Bakker, \& Schaufeli, 2005), life dissatisfaction (Demerouti et al., 2005), work engagement (Bakker, Van Emmerik, \& Euwema, 2006) and flow (Bakker, 2005) rather than on the crossover of discrete emotions, such as, anger, sadness and joy. The crossover of discrete emotion might affect and trigger different levels of employees' psychological states, such as, burnout and engagement.

Many previous research focused only on the crossover between spouses rather than colleagues (e.g., Bakker, Westman, \& Emmerik, 2009a; Bakker \& Demerouti, 2009; Bakker, Shimazu, Demerouti, Shimada, \& Kawakami, 2011; Bakker, Shimazu, Demerouti, Shimada, 
Dayang Siti Aisah Binti Abang Suhaili, Zaiton Hassan, and Shahren Ahmad Zaidi Adruce

\& Kawakami, 2014). Workplace setting may consist of many antecedents or contributors that can trigger employee wellbeing either to engage or burnout. The crossover phenomena or process have been highlighted and captured in previous study only between work and home setting which means the interaction only focus on employee and spouse, rather than capturing the crossover phenomena between employee and colleagues. There are possibilities that colleague may tend to be the stressors that create the conflict. Crossover phenomena within colleagues might affect or influence each other at the workplace, and this situation could be one of the factors that lead to spillover of any psychological state (engagement and burnout) that affect spouses at home. Thus, this present study attempts to examine these phenomena of crossover among colleagues in the organization.

\section{OBJECTIVES}

Based on the statement of problem above, the objective of this paper is to develop a theoretical framework to examine discrete emotional and crossover phenomena among colleagues in predicting employees' wellbeing in the Malaysian organizational context. Specifically, this study attempts to:

i. examine discrete emotion that exists in the organization

ii. identify the existence of positive and negative crossover in the organization

iii. identify the existence of crossover among colleagues

iv. propose a theoretical framework that could help predict the crossover of discrete emotion among employees and implication for human resource development.

\section{METHODOLOGY}

This study used documentary analysis technique to review past studies on spillover-crossover model and discrete emotion. Online databases were used, such as, Proquest, Springer, JSTOR and Emerald to support materials and sources from 2004 to 2015. Keyword used to conduct the literature review, such as, discrete emotion, crossover, burnout and engagement. Fifty articles were reviewed from the databases in this study.

\section{FINDINGS AND DISCUSSION}

\section{Discrete emotion in the workplace}

As mentioned by Bauer (2011), basic emotion could be conceptualized as several discrete emotions, such as, anger, sadness, envy, shame, anxiety, boredom, and jealousy. Employees that possess anger emotions have to regulate it to prevent negative effect on the organization. Anger can lead to the ability that affect and influence workplace behaviors and attitudes (Judge, Scott, \& Ilies, 2006; Kaplan, Bradley, Luchman, and Haynes, 2009).

Theoretically, as mentioned by previous researcher (Spector \& Fox, 2002), emotion plays an important role as mediator to the effects of various aspects of the psychosocial environment, such as, organizational constraints, role stressors, and organizational justice on various dimensions of employee job performance. It is supported by empirical study (Chang, 2013) that shows employees experiencing anger at workplace. Chang (2013) found that emotion is related to burnout. The level of anger (discrete emotion) experienced by employees affects their wellbeing because it increases the intensity of the existing burnout that they have experienced. Employee may feel that the anger is due to 
Dayang Siti Aisah Binti Abang Suhaili, Zaiton Hassan, and Shahren Ahmad Zaidi Adruce

the exposure of job demand or stressor at workplace.

Härtel and Page (2009) implicate that positive emotions, such as, joy and happiness can accelerate a person's recovery from the physiological effects of negative emotions, such as, anger and fear (Fredrickson \& Levenson, 1998; Fredrickson, Mancuso, Branigan, \& Tugade, 2000). In view of this there is a need for employees to have positive thoughts most of the times because this may make a significant impact on their emotions. Positive mind may possess rational thought that can regulate all negative emotions. As we can see, positive emotions can accelerate the physiological effect of negative emotions that could also reduce factors that lead to burnout in the workplace and prevent negative emotions at the workplace from spilling over to the home domain. Positive emotions may lead to positive process crossover and facilitate work engagement.

Happiness is related to employees' work engagement. It is supported by a study conducted by Alfredo, Sanz Vergel, Demerouti and Bakker (2013). They found out that employees' daily work engagement influenced partner's daily happiness through employees' daily happiness. The happiness experienced by employees at workplace may be due to the access to the job resource (eg., supportive supervisor, colleagues) and less job demand or experiencing less burnout.

Moreover, employees experience different level of emotion based of the event or problem faced. Research by Chang (2013) shows that different types of events (students' defiance, hostility, aggression) have the different score or level of teachers' anger. Thus, these events (students' defiance, hostility, aggression) link to specific emotions as anger and frustration of the teacher and increase the intensity of burnout.

\section{Positive and negative crossover and process}

Crossover phenomena involves the transmission process across individuals, whereby it includes demands and consequences of strain crossover to closely related persons (Bakker, Westman, \& Emmerik, 2009b). Most researchers have examined the crossover phenomena within employee's spouses to see the crossover direction that they have experienced, that is, unidirectional (Jones \& Fletcher, 1993) and bi-directional (Westman, Vinokur, Hamilton, \& Roziner, 2004). However, crossover may happen within colleagues at the workplace. Individuals who experienced the crossover phenomena at their workplace may have their emotions or problems spillover at home. It is supported by a study conducted by Emmerik and Peeters (2009). Even though there was little evidence that team-level work demands influence individual work-family conflict (WFC), however, this study was able to show that crossover phenomena exist between employees within teams in the organization and they spillover to home domain.

Crossover phenomena could eventually lead to positive as well as negative experiences (e.g., Bakker, 2005; Bakker, Demerouti, \& Schaufeli, 2005; Demerouti et al., 2005). Bakker and Demerouti (2009) indicated that few studies have really examined the crossover of positive well-being, including life satisfaction (Demerouti et al., 2005), flow at work (Bakker, 2005), and work engagement, such as, a positive, fulfilling, and work-related state of mind which is characterized by vigor, dedication and absorption (Bakker et al., 2005).These studies implicated that positive crossover exists in organizations. Employees who engage with works are likely to show that they are happy. When employees are happy, this happiness may crossover to other 
colleagues and thus will create positive crossover that eventually results in a happy working environment.

Other than that, research work also implicates negative crossover phenomena experienced by some employees, such as, anxiety (Westman et al., 2004), burnout (Bakker \& Schaufeli, 2000; Westman \& Etzion, 1995), distress (Barnett, Raudenbush, Brennan, Pleck, \& Marshall, 1995), depression (Howe, Levy, \& Caplan, 2004), adjustment (Takeuchi, Yun, \& Teslu, 2002), work-family conflict (Hammer, Allen, \& Grigsby, 1997; Westman \& Etzion, 2005), and marital dissatisfaction (Westman et al., 2004b). Exhaustion, cynicism, and lack of professional efficacy are defined as outcomes of burnout (Maslach, Schaufeli, \& Leiter, 2001). There is a need to identify this kind of negative crossover among colleagues and explore the causal mechanisms that likely contribute to creating the negative crossover phenomena. In crossover phenomena, several causal mechanisms can occur, such as, emotional contagion (Hatfield, Cacioppo, \& Rapson,1994 in Bakker \& Demerouti, 2012, p.7) and empathy (Westman \& Vinokur, 1998 in Bakker \& Demerouti, 2012, p. 8). Negative crossover may affect employees' wellbeing and make negative impacts on the organization. For instance, when an employee is not happy because of high job demand from employer, he/she may feel he/she is unfairly treated. He/she may be angry and may express his/her anger at the workplace; at the same time his/her colleagues may be affected directly or indirectly. These situations may lead to the creation of a non-productive workforce because of the non-conducive working environment.

Figure 1 shows the model for the process of crossover phenomena. Employees act as sender and express their emotion toward the other. Colleagues become the medium during the process and respond towards the feeling. Colleagues experience senders' emotion as their own.

\section{Antecedents and employees' wellbeing}

\section{Job demand}

There are several factors that lead to workfamily conflict (WFC). Job demands have been addressed as one of the factors that contribute to crossover effect and workhome interference (Bakker et al., 2005; Montgomery, Peeters, Schaufeli, \& Den Ouden, 2003). Shimazu, Bakker, and Demerouti (2009) found that job demands are related to WFC and poor relationship quality, for instance increased social undermining and decreased social support to a partner of dual-earner parents.

As cited in Xanthopoulou, Bakker, Dollard, Demerouti, Schaufeli, Taris, and Schreurs (2007, p. 767), "job demands have a profound influence on burnout and indirectly lead to increased absenteeism

S-O-R Model for crossover process

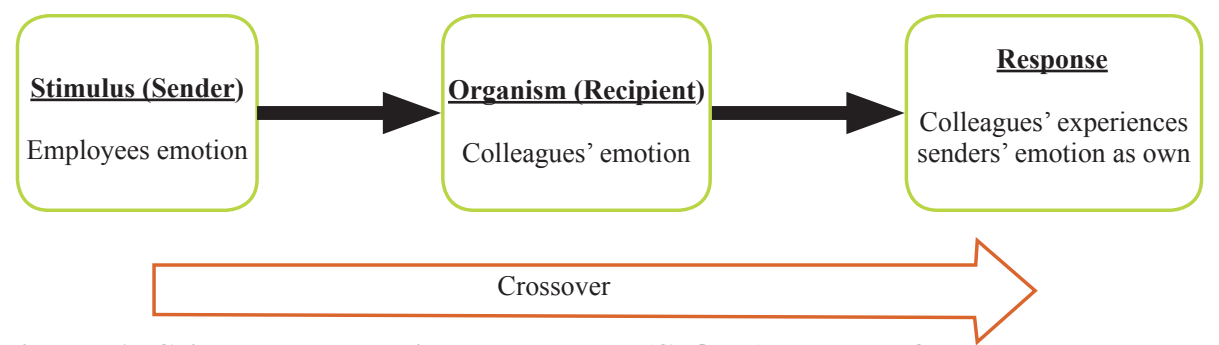

Figure 1: Stimulus, organism, response (S-O-R) model of crossover process. Adapted from Härtel and Page (2009) 
(e.g., Bakker, Demerouti, Boer, \& Schaufeli, 2003) and impaired organizational performance (e.g., Bakker et al., 2004, p.83)"'. As we can see, job demands become one of the factors that may affect the employees' wellbeing. High job demand may cause burnout to employees and affect employees' health and life satisfaction.

Time based and strain-based contributors to $\mathbf{W F C}$

Time-based conflict is a form of resource drain, in which time or attention transferred from one domain to the other hinders performance in that domain but facilitates performance in the other. Strainbased conflict suggests that increased demands from one domain make it more difficult to meet the demands of the other domain, thereby, adversely affecting employee (Thanacoody, Bartram, \& Casimir, 2009). The literature from Greenhaus and Beutell (1985) implicates that WFC exist when, "(a) time devoted to the requirements of one role makes it difficult to fulfill requirements of another; (b) strain from participation in one role makes it difficult to fulfill requirements of another; and (c) specific behaviors required by one role make it difficult to fulfill the requirements of another" (p.76).

Empirical study conducted by Wang, Chang, Fu, and Wang (2012) supported that WFC is associated with burnout. Their study shows that several factors become the factor that contribute to burnout and work family conflict. Burnout may produce negative effects on employees' health and wellbeing.

\section{Family Friendly Policy (FFP)}

Organizational policy plays an important role in supporting employees at workplace. These policies implemented tend to mini- mize the conflict and provide benefits to both parties. Hill, Erickson, Holmes, and Ferris (2010) stated that flexi-time enabled employees to manage their work and family responsibilities by allowing them to reduce work-family conflict and to improve functioning and performance at work and also not neglecting life at home. This shows that the policy implemented is expected to make a positive impact on employees, so the availability of familyfriendly policies in Malaysian workplace may be able to reduce work interference family (Hassan, Dollard, \& Winefield, 2007).

This finding is supported by Morgan (2009 as cited in Downes \& Koekemoer, 2011, p. 2), Johnson and Johnson employees who enjoying work-life balance (WLB) policies took only half as much sick leave as those who did not. Besides, the spirit behind the introduction of work life balance policy is to help organizations reduce absenteeism and occupational stress (Brough, O' Driscoll, \& Kalliath, 2007). The available policy may be one of the factors that can lead to make employees happy otherwise. For instance, if employees are allowed to use flexi-time, then they may be happy because the organizational policy support their working environment, at the same time they may exhibit positive discrete emotional at workplace. As we can see, policy is a very important factor that can contribute to employees' wellbeing as it guides the organization and affects its behavior and culture.

\section{Supervisory support}

Lu, Kao, Cooper, Allen, Lapierre, O'Driscoll, and Spector (2009) implicate that supervisory support enhanced job satisfaction and is able to mitigate the strains that can be caused by work and family conflict for both Taiwanese and British em- 
ployees. Supervisory support seems to be of paramount importance to help employee avoid the existence of negative discrete emotions. Supervisors or employers need to understand that they have to support employees to reduce stress at workplace to avoid work-family conflict. Other than that, being supportive may create positive discrete emotion towards employees. There is a need for employer or supervisor to support the employees at the organization because supervisory support is related to presenteeism at workplace (Caverley, Cunningham, \& MacGregor, 2007).

\section{Theoretical framework to assess the crossover of discrete emotion among employees and HRD implications}

This theoretical framework aims to show the variables that can contribute to how the discrete emotional crossover could predict the outcome of the phenomena.

Based on the review of findings of past research, there is evidence to implicate that discrete emotional crossover can contribute to employees' engagement and burnout at the workplace. Discrete emotion can crossover and increases the intensity of burnout that employees faced. Burnout can reduce employees' performance. The crossover of discrete emotion can occur through emotional contagion. As cited in Emmerik and Peeters, (2009):
Emotional contagion is the tendency to automatically mimic and synchronize expressions, feelings, and attitudes with those of another person, and consequently, to converge emotionally (Hatfield et al., 1994, p.5). Frequent exposure to another person's emotions and paying close attention to them is one of the conditions facilitating contagion (Gorgievski-Duijvesteijin et al., 2000; Hatfield et al., 1994). It is this frequent exposure to another person's emotions and paying close attention to them that is at the core of the contagion model and how the contagion model explains the crossover of both FWC and WFC.

Other than that, Rubino, Wilkin, and Malka (2013) proposed discrete emotion to become the mediator in between job demand and employees' wellbeing. They also mentioned more research need to be done to explore this area. Discrete emotion can trigger the job stressors that exist and it can reduce the individual's capacity to exert control over their work environment and their social relationship between work and home domain. Bakker, Albrecht, and Leiter (2011) suggested that there is a need to understand the crossover or emo-

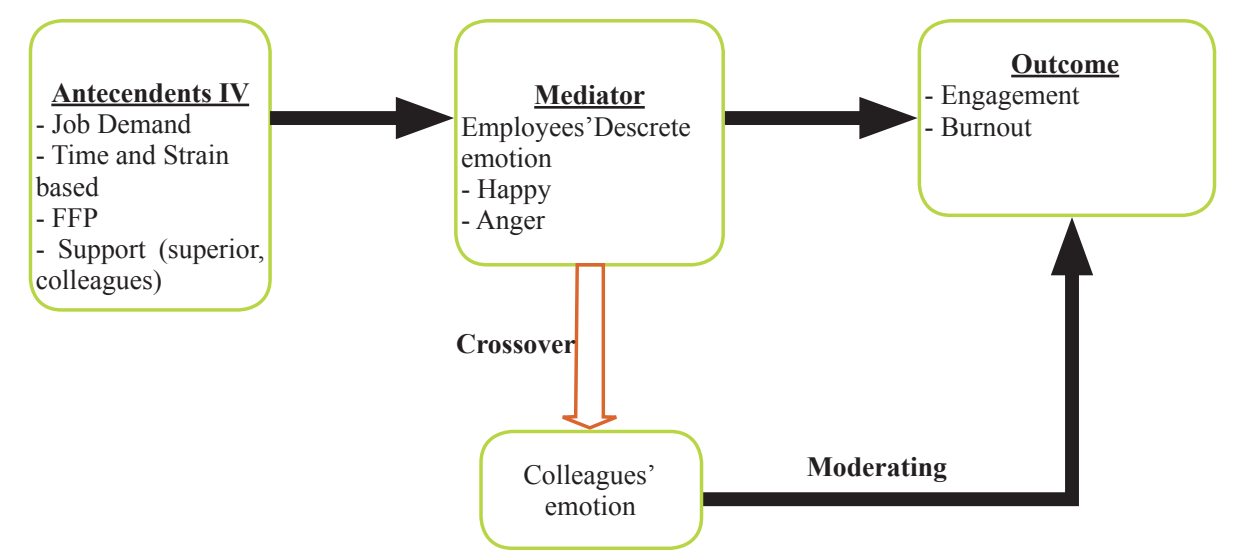

Figure 2: Conceptual Framework 
tional contagion dimensions of engagement in team contexts. Based on this, it may also be applicable to examine burnout dimension in workgroup. It is because employees experience job demand and resource and potential stressor in the organization. This study proposes discrete emotion as mediator and its crossover toward colleagues in predicting employees' burnout and engagement.

HRD practitioners need to pay their attention to the outcome of discrete emotional crossover as work engagement could become a dominant source of competitive advantage. It also has the ability to solve challenging organizational problems, such as, increasing workplace performance and productivity during widespread economic decline (Macey and Schneider, 2008; Macey et al., 2009 as cited in Shuck et al., 2011, p.301). In addition, engaged employees possessed attentiveness and mental absorption in their work (Saks, 2006) and display deep emotional attachment towards their workplace (Wagner \& Harter, 2006; Kahn, 1990 as cited in Shuck, Rocco, \& Albornoz, 2011). Engaged employees make organizations working environment becoming more supportive. Engaged employees may distribute indirectly the values, positive attitudes and emotions. These exhibited values, positive attitudes and emotions can crossover to the other colleagues and create positive workforce energy to the organization. It is expected that this model can be applied by practitioners in managing conflict situation (when conflicts occurs) and create supportive culture that will lead to positive working environment.

HRD practitioners are also required to pay attention to how discrete emotional crossover can be one of the factors that leads to employees' engagement and burnout. Emotional regulation is significant in the organization and employees need skills to do so. Consequently, it can reduce the level of demand that can lead to burnout of employees.

\section{CONCLUSION}

As a conclusion, it is expected that this paper could help HRD practitioners understand the discrete emotion and the process of how crossover occurs. The knowledge about discrete emotional crossover is significant to the organizational performance. The consequences of crossover phenomena will occur if there is a lack of knowledge in identifying the factors and process. The findings from this study are expected to provide knowledge and insights of discrete emotions and their effect on individuals and organizations to ensure better employees' satisfaction and better workplace environment. It is also hoped that other researchers in this field could test empirically the framework suggested in this study. This study only focuses on discrete emotion in the crossover process rather than discrete emotion for both spillover and crossover phenomena. It is recommended that future study may include spillover of discrete emotion in predicting organizational outcomes.

\section{REFERENCES}

Alfredo, R. M., SanzVergel, A. I., Demerouti, E., \& Bakker, A. B. (2013). Engaged at work and happy at home: A spillover-crossover model. Journal of Happiness Studies, 15(2), 271-283 .

Bakker, A., \& Schaufeli, W. (2000). Burnout contagion processes among teachers. Journal of Applied Social Psychology, 30(11), 2289-2308.

Bakker, A. B., Demerouti, E., de Boer, E., \& Schaufeli, W. B. (2003). Job demand and job resources as 
Dayang Siti Aisah Binti Abang Suhaili, Zaiton Hassan, and Shahren Ahmad Zaidi Adruce

predictors of absence duration and frequency. Journal of Vocational Behavior, 62(2), 341-356.

Bakker, A. B., Demerouti, E., \& Verbeke, W. (2004). Using the Job Demands-Resources Model to predict burnout and performance. Spring, 43(1), 83-104.

Bakker, A. B., Demerouti, E., \& Schaufeli, W. B. (2005). The crossover of burnout and work engagement among working couples. Human Relations, 58(5), 661-689.

Bakker, A .B. (2005). Flow among music teachers and their students: the crossover of peak experiences, Journal of Vocational Behavior, 66(1), 26-44.

Bakker, A.B., Van Emmerik, I. J. H., \& Euwema, M.C. (2006). Crossover of burnout and engagement in work teams. Work \& Occupations, 33(4), 464-89.

Bakker, A. B., \& Demerouti, E. (2009). The crossover of work engagement between working couples: A closer look at the role of empathy. Journal of Managerial Psychology, 24(3), 220-236.

Bakker, A. B., Westman, M., \& Emmerik, I. J. H. Van. (2009a). Advancements in crossover theory. Journal of Managerial Psychology, 24(3), 206-219.

Bakker, A. B., Westman, M., \& Emmerik, I. J. H. Van. (2009b). Advancements in crossover theory. Journal of Managerial Psychology, 24(3), 206-219.

Bakker, A. B., Albrecht, S. L., \& Leiter, M. P. (2011). Key questions regarding work engagement. European Journal of Work and Organizational Psychology, 20(1), 4-28.

Bakker, A. B., Shimazu, A., Demerouti, E., Shimada, K., \& Kawakami, N. (2011). Crossover of work engage- ment among Japanese couples: Perspective taking by both partners. Journal of Occupational Health Psychology, 16(1), 112-25.

Bakker, A. B., \& Demerouti, E. (2012). The Spillover-Crossover Model. Vasa. Retrieved from http://medcontent.metapress.com/index/ A65RM03P4874243N.pdf.

Bakker, A. B., Shimazu, A., Demerouti, E., Shimada, K., \& Kawakami, N. (2014). Work engagement versus workaholism: A test of the spillover-crossover model. Journal of Managerial Psychology, 29(1), 63-80.

Barnett, R. C., Raudenbush, S. W., Brennan, R. T., Pleck, J. H., \& Marshall, N. L. (1995). Change in job and marital experiences and change in psychological distress: A longitudinal study of dual-earner couples. Journal of Personality and Social Psychology, 69(5), 839-850.

Bauer, J. A. (2011). The role of discrete emotions in predicting counterproductive work behavior (Masters Thesis, University of South Florida, United States). Retrieved from http://scholarcommons.usf. edu/etd.3002.

Brough, P., O'Driscoll, M., \& Kalliath, T. (2007). Work-family conflict and facilitation: Achieving work-family balance. In Advances in Organizational Psychology, eds. A. I. Glendon, B. M. Thompson, and B. Myors, 73-92. Brisbane: Australian Academic Press.

Caverley, N., Cunningham, J.B., \& MacGregor, J.N. (2007). Sickness presenteeism, sickness absenteeism, and health following restructuring in a public service organization. Journal of Management Studies, 44(2), 304-319. 
Dayang Siti Aisah Binti Abang Suhaili, Zaiton Hassan, and Shahren Ahmad Zaidi Adruce

Chang, M. L. (2013). Toward a theoretical model to understand teacher emotions and teacher burnout in the context of student misbehavior: Appraisal, regulation and coping. Motivation and Emotion, 37(4), 799-817.

Chin, R. J. (2015). Examining teamwork and leadership in the fields of public administration, leadership, and management. Team Performance Management: An International Journal, 21(3), 199-216.

Costa, P. L., Passos, A. M., \& Barata, M. C. (2015). Multilevel influences of team viability perceptions. Team Performance Management, 21(1), 19-36.

Demerouti, E., Bakker, A. B., \& Schaufeli, W. B. (2005). Spillover and crossover of exhaustion and life satisfaction among dual-earner parents. Journal of Vocational Behavior, 67(2), 266-289.

Downes, C., \& Koekemoer, E. (2011). Work-life balance policies: Challenges and benefits associated with implementing flexitime. SA Journal of Human Resource Management, 9(1), 1-13.

Emmerik, I. J. H. Van, \& Peeters, M. C. W. (2009). Crossover specificity of team-level work-family conflict to individual-level work-family conflict. Journal of Managerial Psychology, 24(3), 254-268.

Ezziane, Z., Maruthappu, M., Gawn, L., Thompson, E. A., Athanasiou, T., \& Warren, O. J. (2012). Building effective clinical teams in healthcare. Journal of Health Organization and Management, 26(4), 428436.

Fredrickson, B. L., \& Levenson, R. W. (1998). Positive emotions speed recovery from the cardiovascular sequelae of negative emotions.
Cognition \& Emotion, 12(2), 1-25.

Fredrickson, B. L., Mancuso, R. A., Branigan, C., \& Tugade, M. M. (2000). The undoing effect of positive emotions. Motivation and Emotion, 24(4), 237-258.

Gorgievski-Duijvesteijin, M. J., Giesen, C. W. M., \& Bakker, A. B. (2000). Financial problems and health complaints among farm couples: results of a 10-yr follow-up study. Journal of Occupational Health Psychology, 5(3), 359-373.

Greenhaus, J. H., \& Beutell, N. J. (1985). Sources of conflict between work and family roles. Academy of Management Review.

Gross, J. J., \& John, O. P. (2003). Individual differences in two emotion regulation processes: Implications for affect, relationships, and wellbeing. Journal of Personality and Social Psychology, 85(2), 348-362. Hammer, L. B., Allen, E., \& Grigsby, T. D. (1997). Work-family conflict in dual-earner couples: Within individual and crossover effects of work and family. Journal of Vocational Behavior, 50(2), 185-203.

Härtel, C. E. J., \& Page, K. M. (2009). Discrete emotional crossover in the workplace: The role of affect intensity. Journal of Managerial Psychology, 24(3), 237-253.

Hassan, Z., Dollard, M., \& Winefield, T. (2007). Work-family policy and work-family conflict in the Malaysian private sector: A preliminary study. Proceedings of the 7th Industrial and Organisational Psychology 1st Asia Pacific Congress on Work and Organisational Psychology, Adelaide.

Hatfield, E., Cacioppo, J.T., \& Rapson, R.L. (1994). Emotional Contagion. Cambridge University Press, New 
York, NY.

Hill, E.J, Erickson, J. J, Holmes, E. K., \& Ferris, M. (2010). Workplace flexibility, work hours and work-life conflict: Finding an extra day or two. Journal of Family Psychology, 24(3), 349-358.

Howe, G., Levy, M., \& Caplan, R. (2004). Job loss and depressive symptoms in couples: Common stressors, stress transmission, or relationship disruption?. Journal of Family Psychology, 18(4), 639-650.

Joiner, T. E. Jr., \& Katz, J. (1999). Contagion of depressive symptoms and mood: Meta-analytic review and explanations from cognitive, behavioral, and interpersonal viewpoints. Clinical Psychology: Science and Practice, 6(2), 149-164.

Jones, F., \& Fletcher, B. (1993). Transmission of occupational stress: A study of daily fluctuations in work stress and strain and their impact on marital partners. In H.J. Schroder, K. Rescke, M. Johnston \& S. Maes (Eds.) Health psychology: Potential diversity (pp. 328-338). Regensburg: Roderer Verlag.

Judge, T. A., Scott, B. A., \& Ilies, R. (2006). Hostility, job attitudes, and workplace deviance: Test of a multilevel model. The Journal of Applied Psychology, 91(1), 126138.

Kaplan, S., Bradley, J. C., Luchman, J. N., \& Haynes, D. (2009). On the role of negative affectivity in job performance: A meta-analytic investigation. Journal of Applied Psychology 94(1), 162-176.

Lee, K., \& Allen, N. J. (2002). Organizational citizenship behavior and workplace deviance: The role of affect and cognitions. Journal of Applied Psychology, 87(1), 131-142.
Lu, L., Kao, S.F., Cooper, C. L., Allen, T. D., Lapierre, L. M., O’Driscoll, M., \& Spector, P. E. (2009). Work resources, work-to-family conflict, and its consequences: A TaiwaneseBritish cross-cultural comparison. International Journal of Stress Management, 16(1), 25-44.

Macey, W. H., \& Schneider, B. (2008). The meaning of employee engagement. Industrial and Organizational Psychology, 1(1), pp. 3-30.

Macey, W. H., Schneider, B., Barbera, K. M., \& Young, S. A. (2009). Employee engagement: Tools for analysis, practice, and competitive advantage. Wiley, Malden, MA.

Maslach, C., Schaufeli, W. B., \& Leiter, M. P. (2001). Job burnout. Annual Review of Psychology, 52(1): 397422.

Montgomery, A. J., Peeters, M. C. W., Schaufeli, W. B., \& Den Ouden, M. (2003). Work- home interference among newspaper managers: Its relationship with burnout and engagement. Anxiety, Stress, and Coping, 16(2), 195-211.

Rubino, C., Wilkin, C. L., \& Malka, A. (2013). Under pressure: Examining the mediating role of discrete emotions between job conditions and well-being. In The Role of Emotion and Emotion Regulation in Job Stress and Well Being, 11, pp. 195-223.

Salas, E., Cooke, N. J., \& Rosen, M. A. (2015). On teams, teamwork, and team performance: Discoveries and developments. Human Factors, 50(3), 540-547.

Schutte, N. S., Manes, R. R., \& Malouff, J. M. (2009). Antecedent-focused emotion regulation, response modulation and well-being. Current Psychology, 28(1), 21-31. 
Dayang Siti Aisah Binti Abang Suhaili, Zaiton Hassan, and Shahren Ahmad Zaidi Adruce

Shimazu, A., Bakker, A. B., \& Demerouti, E. (2009). How job demands affect an intimate partner: A test of the spillover-crossover model in Japan. Journal of Occupational Health, 51(3), 239-48. Retrieved from http://www.ncbi.nlm.nih.gov/ pubmed/19390160.

Shimazu, A., \& Schaufeli, W. B. (2009). Is workaholism good or bad for employee well-being? The distinctiveness of workaholism and work engagement among Japanese employees. Industrial Health, 47(5), 495-502. Retrieved from http://www.ncbi.nlm.nih.gov/ pubmed/19834258.

Shuck, M. B., Rocco, T. S., \& Albornoz, C. A. (2011). Exploring employee engagement from the employee perspective: Implications for HRD. Journal of European Industrial Training, 35(4), 300-325.

Spector, P. E., \& Fox, S. (2002). An emotion-centered model of voluntary work behavior: Some parallels between counterproductive work behavior (CWB) and organizational citizenship behavior (OCB). $\mathrm{Hu}$ man Resources Management Review, 12(2), 269-292.

Takeuchi, R., Yun, S., \& Teslu, P. T. (2002). An examination of crossover and spillover effects of spousal and expatriate cross-cultural adjustment on expatriate outcomes. Journal of Applied Psychology, 87(510), 655-666.

Thanacoody, P. R., Bartram, T., \& Casimir, G. (2009). The effects of burnout and supervisory social support on the relationship between workfamily conflict and intention to leave: A study of Australian cancer workers. Journal of Health Organisation and Management,
23(1), 53-69.

Vecchio, R. P. (2000). Negative emotion in the workplace: Employee jealousy and envy. International Journal of Stress Management, 7(3), 161-179.

Wang, Y., Chang, Y., Fu, J., \& Wang, L. (2012). Work-family conflict and burnout among Chinese female nurses: The mediating effect of psychological capital. BMC Public Health, 12(1), 915.

Westman, M. (2001). Stress and strain crossover. Human Relations, 54(6), 717-751

Westman, M., \& Etzion, D. (1995). Crossover of stress, strain and resources from one spouse to another. Journal of Organizational Behavior, 16(2), 169-181.

Westman, M., Vinokur, A. D., Hamilton, V. L., \& Roziner, I. (2004a). Crossover of marital dissatisfaction during military downsizing among Russian army officers and their spouses. The Journal of Applied Psychology, 89(5), 769-79.

Westman, M., Vinokur, A. D., Hamilton, V. L., \& Roziner, I. (2004b). Crossover of marital dissatisfaction during military downsizing among Russian army officers and their spouses. The Journal of Applied Psychology, 89(5), 769-779.

Westman, M., \& Etzion, D. (2005). The crossover of work-family conflict from one spouse to the other. Journal of Applied Social Psychology, 35(9), 1936-1957.

Xanthopoulou, D., Bakker, A. B., Dollard, M. F., Demerouti, E., Schaufeli, W. B., Taris, T. W., \& Schreurs, P. J. G. (2007). When do job demands particularly predict burnout?: The moderating role of job resources. Journal of Managerial Psychology, 22(8), 766-786. 